\title{
Somatic cell count-based selection reduces susceptibility to energy shortage during early lactation in a sheep model
}

\author{
J. Bouvier-Muller, ${ }^{*} \dagger$ C. Allain, ${ }^{*}$ F. Enjalbert, ${ }^{*}$ Y. Farizon, ${ }^{*}$ D. Portes, $\ddagger$ G. Foucras, $\dagger$ and R. Rupp ${ }^{* 1}$ \\ ${ }^{*}$ GenPhySE, Université de Toulouse, INRA, INPT, ENVT, Castanet Tolosan, F-31326, France \\ †Interactions Hôtes-Agents Pathogènes (IHAP), Université de Toulouse, ENVT, Toulouse, F-131076, France \\ ‡Domaine de La Fage, INRA, Roquefort sur Soulzon, F-12250, France
}

\section{ABSTRACT}

During the transition from late gestation to early lactation ruminants experience a negative energy balance (NEB), which is considered to increase susceptibility to mammary infections. Our previous study in 2 divergent lines of sheep selected for high and low somatic cell score (SCS) suggested an association between the response to NEB and genetic susceptibility to mastitis. Forty-eight early-lactation primiparous dairy ewes from the 2 SCS genetic lines were allocated to 2 homogeneous subgroups - an NEB group, which was energy restricted and received $60 \%$ of the energy requirements for $15 \mathrm{~d}$, and a control-fed group - to obtain 4 balanced groups of 12 ewes: high-SCS positive energy balance, low-SCS positive energy balance, high-SCS NEB, and low-SCS NEB. High-SCS ewes showed greater weight loss and increased plasmatic concentrations of $\beta$-hydroxybutyrate and nonesterified fatty acids than low-SCS ewes when confronted with an induced NEB. The aim of this study was to further characterize this interaction by combining transcriptomic and phenotypic data with a generalized partial least squares discriminant analysis using mixOmics package framework. A preliminary analysis using 3 blocks of phenotypes (fatty acids, weight and production, blood metabolites) revealed a high correlation between fat-to-protein ratio, $\beta$-hydroxybutyrate, and nonesterified fatty acids concentrations with milk long-chain fatty acid yields. These phenotypes allowed good discrimination of the energy-restricted high-SCS ewes and confirmed a high level of adipose tissue mobilization in this group. A second analysis, which included RNA-seq data, revealed high correlations between the long-chain fatty acid yields in milk and $P D K_{4}, C P T 1 A$, SLC25A20, KLF10, and KLF11 expression, highlighting the relationship between mobilization of body reserves and enhanced fatty acids utilization for energy production in blood cells. Finally, analysis of milk com-

Received July 11, 2017.

Accepted November 20, 2017.

${ }^{1}$ Corresponding author: rachel.rupp@toulouse.inra.fr position measured in 1,025 ewes from the 2 genetic lines over 10 yr confirmed significant higher fat-to-protein ratio in high-SCS ewes in early lactation. Altogether, our results strongly confirmed a genetic link between susceptibility to mastitis and metabolic adaptation to energy shortage. Improving genetic resistance to mastitis using SCS should be accompanied by a favorable effect on the response to metabolic stress, especially in highly stressful early lactation. Moreover, this study suggests that the fat-to-protein ratio could be used as a low-cost tool for monitoring energy balance and ketosis during this critical phase of lactation.

Key words: mastitis resistance, negative energy balance, dairy ruminant, data integration

\section{INTRODUCTION}

Mastitis, an inflammation of the mammary gland, is caused mainly by bacteria that proliferate in the gland lumen following colonization of the teat canal. This disorder is the most costly and frequent infectious disease of dairy cattle (Wells et al., 1998; Barkema et al., 2009) and sheep (Bergonier et al., 2003). Although much work has been carried out in dairy ruminants to understand the complex physiological and cellular events that occur in the mammary gland in response to pathogens (Kehrli and Shuster, 1994; Sordillo, 2005), the protective mechanisms are still obscure. Data in the literature, however, corroborate the importance of a rapid influx of neutrophils and macrophages into the mammary gland to allow effective and early clearance of the pathogen and to control the inflammatory process (Paape et al., 2002; Wellnitz and Bruckmaier, 2012). This massive cell recruitment in the udder leads to a dramatic increase in the milk SCC. Accordingly, SCC has been widely advocated as an easy-to-measure tool for predicting mastitis and discriminating between chronically infected and noninfected animals (Kehrli and Shuster, 1994; Bergonier and Berthelot, 2003).

The existence of a genetic basis for mastitis susceptibility has been well documented in dairy ruminants (Mrode and Swanson, 1996; Heringstad et al., 2000; 
Rupp and Boichard, 2003). The estimated heritability of SCC, one of the most widely studied predictors, ranges from 10 to 20\% (Rupp and Foucras, 2010) and is genetically strongly positively correlated with resistance to mastitis. In this context, a divergent selection of Lacaune dairy sheep was developed based on extreme breeding values of the SCS (Rupp et al., 2009). In particular, milk bacteriology showed that the high-SCS line has a higher rate of mammary infections in natural conditions, which is associated with a lower capacity for bacterial clearance during experimental challenges compared with the low-SCS line (Bonnefont et al., 2011).

The risk of dairy ruminants developing mastitis is increased during the periparturient period, when most animals experience some degree of negative energy balance (NEB). This is due to a low feed intake relative to high energy demands for growth of the fetus and uterus and milk synthesis, especially in high-yielding animals (Drackley, 1999). The severity and duration of NEB leads to extensive mobilization of fatty acids (FA) from the adipose tissue and results in higher blood nonesterified FA (NEFA) or BHB concentrations (Dann et al., 2006). There is growing evidence of a relationship between severe NEB, impairment of the immune response, and an increased risk of mastitis in early lactation, in particular in dairy cows (Suriyasathaporn et al., 2000; Jánosi et al., 2003; Nyman et al., 2008).

A genetic association between mastitis susceptibility and energy metabolism was also suggested in a previous study in dairy ewes (Bouvier-Muller et al., 2016). This report described the consequences of experimentally induced NEB during early lactation on production traits and metabolic response in high-SCS and low-SCS ewes. A noteworthy interaction between genetic background and energy balance on metabolic parameters and BW was demonstrated. High-SCS ewes showed a greater decrease in BW and higher NEFA and BHB concentrations than low-SCS ewes when subjected to NEB. However, the mechanisms underlying the relationship between energy balance and mastitis susceptibility remained unclear.

In the present study, additional phenotypes such as milk FA composition and blood RNA-seq transcriptomic profiling were scrutinized to provide additional insight into these mechanisms. A sparse partial least squares-discriminant analysis (sPLS-DA) model, based on the integration of multiple phenotypes and transcriptomic data sets, was used to describe the interaction between genetic background for mastitis susceptibility and energy balance. Field data on the genetic lines were also analyzed to confirm our hypothesis of a genetic dependence of ketosis frequency in relation to susceptibility to mammary infection.

\section{MATERIALS AND METHODS}

All procedures involving animals received approval from the Ethics Committee on Animal Experimentation of Toulouse (France), agreement no. 01557/01.

\section{Experimental Design}

A detailed description of the experimental design can be found in Bouvier-Muller et al. (2016). Briefly, 48 primiparous Lacaune ewes from each of 2 genetic lines (high SCS and low SCS; Rupp et al., 2009) were allocated to 2 groups per line 2 wk after lambing according to milk yield, milk composition, BW, and litter size. One group received a control (positive energy balance; PEB) diet that met energy requirements, and the other group (NEB) received a low-energy diet that met only $60 \%$ of their energy requirements. This resulted in 4 balanced groups of 12 ewes: high-SCS PEB, low-SCS PEB, high-SCS NEB, and low-SCS NEB. Both diets met the protein requirements. After $10 \mathrm{~d}$ on either the NEB or PEB diet, the healthiest half-udder in all ewes was injected with a sterile solution of Pam3CSK4 (10 $\mu \mathrm{g} / \mathrm{mL}$; InVivogen, Toulouse, France) and muramyl dipeptide $(10 \mu \mathrm{g} / \mathrm{mL}$; InVivogen $)$ to induce local inflammation. As shown in Figure 1, the first day of restriction was referred to as d 0 in the experiment timeline.

\section{Phenotypes and Sample Collection for Blood Metabolites Analyses}

A detailed description of the phenotypes collection can be found in Bouvier-Muller et al. (2016). Milk yield, fat, and protein contents and SCC were measured on $\mathrm{d}-2,8$, and 14 . The SCC were measured with a Fossomatic cell counter (Foss, Hillerød, Denmark). Daily values of SCC, fat, and protein contents were calculated as the average of the morning and evening milking values weighted by milk yield. The daily fatto-protein ratio was calculated from the daily averages for fat and protein contents. Daily SCC data were normalized as follows to give a daily SCS: SCS $=3+$ $\log 2(\mathrm{SCC} / 100,000)$.

The NEB was characterized by weighing the ewes on $\mathrm{d}-1,8$, and 14. During the restriction period, BW was corrected in NEB ewes by adding their average decrease in $\mathrm{BW}$ between $\mathrm{d}-1$ and $\mathrm{d} 1(3.3 \mathrm{~kg})$ to compensate for the decrease in digestive tract contents due to the lower DMI. Body condition score was assessed on d $-10,6$, and 14 using the 5 -point scale proposed by Russel et al. (1969). Blood was sampled from the jugular vein on $\mathrm{d}-3,11$, and 14 before the morning milking, and the serum was analyzed for glucose, insulin, NEFA, 


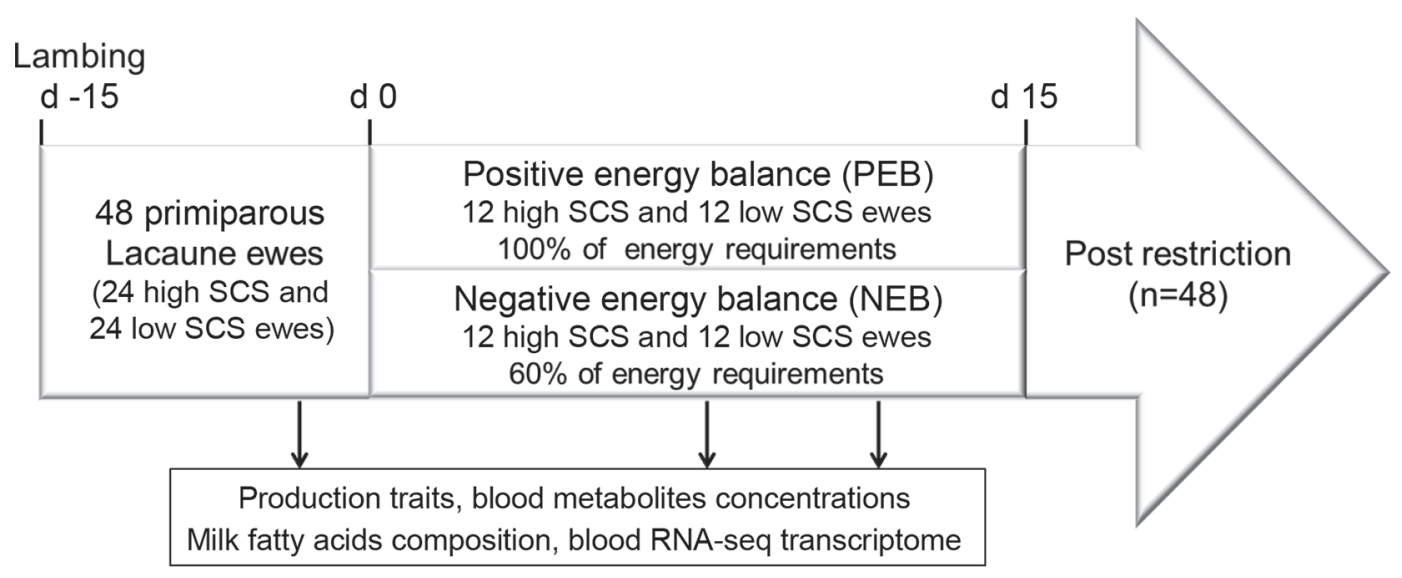

Figure 1. Experiment timeline.

and BHB as previously described by Bouvier-Muller et al. (2016).

\section{Collection of FA Data}

Milk samples for FA analysis were collected on d -2 , 8 , and 14 and methylated in situ using the procedure described by Jenkins (2010). Nonadecanoic acid (Sigma-Aldrich, St. Louis, MO) was used as the internal standard. The FAME were quantified by GC (Agilent $6890 \mathrm{~N}$, equipped with a model 7683 auto injector, Network GC System; Agilent Technologies Inc., Santa Clara, CA) using a fused silica capillary column (100 $\mathrm{m} \times 0.25 \mathrm{~mm}$ i.d., $0.20-\mu \mathrm{m}$ film thickness; CP-Sil 88; Agilent Technologies). For analysis, the flame ionization detector temperature was maintained at $260^{\circ} \mathrm{C}$ and the injector at $255^{\circ} \mathrm{C}$; the split ratio was 1:50. Hydrogen was used as the carrier gas with a constant flow of 1 $\mathrm{mL} / \mathrm{min}$. The samples were injected in $1 \mu \mathrm{L}$ of hexane. The initial temperature of the oven was $60^{\circ} \mathrm{C}$, which was maintained for $2 \mathrm{~min}$; it was then increased by $8^{\circ} \mathrm{C} / \mathrm{min}$ to $150^{\circ} \mathrm{C}$, kept at $150^{\circ} \mathrm{C}$ for $12 \mathrm{~min}$, increased by $2^{\circ} \mathrm{C} / \mathrm{min}$ to $175^{\circ} \mathrm{C}$, held at $175^{\circ} \mathrm{C}$ for $20 \mathrm{~min}$, increased by $5^{\circ} \mathrm{C} / \mathrm{min}$ to $225^{\circ} \mathrm{C}$, held at $225^{\circ} \mathrm{C}$ for 10 min, and finally increased by $5^{\circ} \mathrm{C} / \mathrm{min}$ to $240^{\circ} \mathrm{C}$ and maintained at $240^{\circ} \mathrm{C}$ for $10 \mathrm{~min}$. Peaks were identified and quantified by comparison with commercial standards (Sigma-Aldrich) except C18:1, trans-4 to trans 8-C18:1, trans-12 to trans-16 C18:1, cis-12 C18:1, and cis-15 C18:1 FA, which were identified by order of elution as described in Troegeler-Meynadier et al. (2014). Odd-chain FA were summed as branched chain (iso and anteiso from C13:0 to C17:0) and straight chain (from C7:0 to C17:0). Fatty acid proportions were then multiplied by fat content, milk yield, and 0.933, which is the FA-to-fat content ratio in milk (Glasser et al., 2007), to obtain FA yields and analyze FA exportation to the milk.

\section{Collection of RNA-seq Data}

Details on the collection of RNA-seq data have been described by Bouvier-Muller et al. (2017). The RNA-seq samples were collected from 6 ewes in each of the 4 groups (24 ewes total). The ewes in these 4 subgroups were selected to be representative of the initial groups for milk production, BHB, and NEFA concentrations. Briefly, blood samples were collected by jugular venipuncture at 3 time points $(\mathrm{d}-3,11$, and 12). Total RNA was isolated from blood samples using the commercially available NucleoSpin RNA Blood kit (Macherey-Nagel, Düren, Germany) according to the manufacturer's protocol. The cDNA libraries were prepared from high-quality RNA using an Illumina TruSeq RNA sample prep kit following the manufacturer's instructions (Illumina, San Diego, CA). Individual RNA-seq libraries were sequenced in triplicate at $100 \mathrm{bp} /$ sequence paired-end reads using an Illumina HiSeq 2500 sequencer (Illumina, TruSeq PE Cluster Kit v. 3, cBot, and TruSeq BS Kit v3; http://www.illumina.com/) at the GenoToul genomic platform (Castanet-Tolosan, France). Input reads were aligned to the ovine reference genome (Ensembl v. 74; http://www.ensembl.org/Ovis_aries/Info/Index) using STAR (v. 2.4.0; http://labshare.cshl.edu/shares/ gingeraslab/www-data/dobin/STAR/STAR.posix/ doc/STARmanual.pdf). The alignments were sorted with Samtools (v. 0.1.19; http://samtools.github .io). Raw counts for the genes were obtained using the FeaturesCount software package (http://subread .sourceforge.net/) and the Ensembl v. 74 annotation of the ovine genome. The R (3.3.1; http:/ / www.R-project .org) package, DESeq2 (1.12.4), was applied to normalize the RNA-seq data by using a negative binomial distribution to model biological and technical variance for the count data after removing any genes that had zero read counts for all samples. 


\section{Data Integration and Discriminant Analysis}

A supervised classification by sPLS-DA was conducted to classify the group's segregation and to identify the most important phenotypes and genes that best discriminated the 4 groups (high-SCS PEB, low-SCS PEB, high-SCS NEB, and low-SCS NEB). The sPLS$\mathrm{DA}$ was applied using the $\mathrm{R}$ (version 3.3.1) package MixOmics (version 1.6.3) that is dedicated to the integrative analysis of "omics" data (Lê Cao et al., 2009).

The sPLS-DA uses a matrix of features $(\mathrm{X})$ and a group vector (factor), indicating the group of each sample, to select the most predictive or discriminative features (phenotypes or genes) in the data that help classify the samples (Lê Cao et al., 2011). Unlike principal component analysis, which focuses on variance maximization of the features alone, the sPLS-DA models covariance maximization between the matrix of features and the factor to estimate the parameters of a linear regression model and therefore provide a regression extension of principal component analysis. Plotloading was used to visualize the weights of each selected variable on each component and to determine the variables that best discriminated the groups in the different data sets.

Lê Cao et al. (2009) included more than 2 blocks of features in a generalized sPLS-DA to integrate multiple data sets measured on the same samples and classify a discrete outcome (block sPLS-DA or Diablo; http://mixomics.org/mixdiablo/). From the regression framework, the scatterplot of given components allows method validation by checking that the correlation between blocks of features has been maximized by the method. The generalized Pearson correlation coefficient for matrices (RV coefficient) may be used to estimate the correlation between 2 transformed blocks of features (Robert and Escoufier, 1976). The association between variables was computed using a similarity score based on the coordinates of the variables on the axis defined by the principal components. Correlation circle plots were used to visualize these correlations between variables of different blocks.

First, sPLS-DA was used to integrate 3-block data sets - namely, the blood metabolites (NEFA, BHB, glucose, insulin), the production traits (BCS, weight, milk yield, milk protein yield, fat yield, protein content, fat content, fat-to-protein ratio, milk SCS), and the milk FA composition data sets - in 48 ewes using 3 time points $(\mathrm{d}-3,11$, and 12$)$. The stability of the estimated error rates to the number of variables in the milk FA data set had been previously plotted to determine the number of variables to keep for the sPLS-DA analysis. Thus, 10 variables in this data set were retained for the sPLS-DA analysis.
A meta-phenotype data set was created with the blood metabolites data set, the production traits data set, and the 10 milk FA yields chosen during the first sPLS-DA analysis. A second sPLS-DA was carried out on this new meta-phenotype block data set and the normalized RNA-seq data set in 24 ewes (6 ewes from each of the 4 groups) using the same 3 time points as above. As in the first analysis, the stability of the estimated error rates according to the number of variables in the RNA-seq data set had been previously plotted, and 10 genes had been retained for this second analysis.

\section{Reverse-Transcription Quantitative PCR}

Eight genes were assessed by reverse-transcription quantitative PCR on blood samples from the 24 ewes that had not been used for RNA-seq. Quantitative PCR and data processing were as reported by BouvierMuller et al. (2017). Specific details of primer design can been found in Supplemental Table S1 (https:// doi.org/10.3168/jds.2017-13479). Analyses of variance using linear mixed models with the $\mathrm{R}$ (version 3.1.2) Bioconductor package nlme (version 3.1) were applied to determine the effects of the group on gene expression obtained by quantitative PCR. To test the effect of the group, the model included the fixed effects of date (d -4, 11, and 12) and group (high-SCS PEB, low-SCS PEB, high-SCS NEB, and low-SCS NEB) and an individual milk production reference. For each ewe, individual milk production reference was the average of the last 3 milk yields recorded before energy restriction. Statistical differences were declared as significant and highly significant at $P<0.05$ and $P<0.01$, respectively. Trends toward significance at $P<0.10$ were open to discussion.

\section{Field Data Analysis for Fat-to-Protein Ratio}

Records of milk production and SCC were obtained during the official milk recording in high and low-SCS lines of ewes at the INRA experimental facility of La Fage (UE321, Roquefort, France). Lambs were suckled during a 3 -wk period. Ewes were then milked twice a day, and the official milk recordings were available from 28 DIM onward. The milk production traits recorded were test-day milk yield, fat, and protein contents at the morning milking, measured every $3 \mathrm{wk}$, from 28 to 220 DIM. However, 2 time points in early lactation (morning test days), at 6 and 20 DIM on average, were also available for 58 and 70 primiparous ewes, respectively. Thus, a total of 16,402 test days from 1,025 primiparous and 715 multiparous ewes recorded between 2005 and 2016 were available. Analyses were conducted separately on primiparous and multiparous ewes. A lin- 
ear mixed model (PROC MIXED in SAS; SAS Institute Inc., Cary, NC) was used to test the effect of genetic lines on repeated measures of fat-to-protein ratio with special attention paid to early lactation. The following fixed effects were tested: genetic line, DIM (10 at 3-wk intervals from 6 to 220 DIM), parity (in multiparous ewes), year, milk production, number of suckled lambs (1 vs. 2 or more), and all interaction terms, including the genetic line $\times$ DIM interaction.

\section{RESULTS}

\section{Phenotypic Data Integration}

The sPLS-DA was used to integrate the blood metabolites, production traits, and milk FA composition data sets. The purpose of this analysis was to identify the phenotypes that most readily discriminated the 4 groups (high-SCS PEB, low-SCS PEB, high-SCS NEB, and low-SCS NEB) on 48 ewes using the 3 time points. Percentages of variance that explain the first and second principal components were respectively 0.61 and
0.22 in the metabolite data set, 0.54 and 0.28 in the FA data set, and 0.4 and 0.27 in the production traits data set.

Figure 2 shows the weight of the variables in the first PC, which best separated the 4 groups. Fat content, fat-to-protein ratio, fat yield, and BHB and NEFA concentrations were the most discriminant variables in the production trait and blood metabolite data sets, respectively. Long-chain FA (such as cis-9 C18:1, C17:0, $\mathrm{C} 18: 0$, anteiso $\mathrm{C} 17: 0$, and $\mathrm{C} 16: 1)$ yields were the most informative variables in the milk FA data set. These variables contributed the most to distinguish high-SCS NEB ewes from the 3 other groups according to the sPLS-DA analysis.

This analysis revealed a high correlation between the 3 data sets, with RV coefficients ranging from 0.8 to 0.94 . Figure 3 shows the correlations between the variables from the 3 different blocks. Cutoff was set at 0.9 to ensure clarity. The correlation table is displayed in Supplemental Table S2 (https://doi.org/10.3168/jds .2017-13479). The BHB and NEFA concentrations were highly positively correlated with fat-to-protein ratio

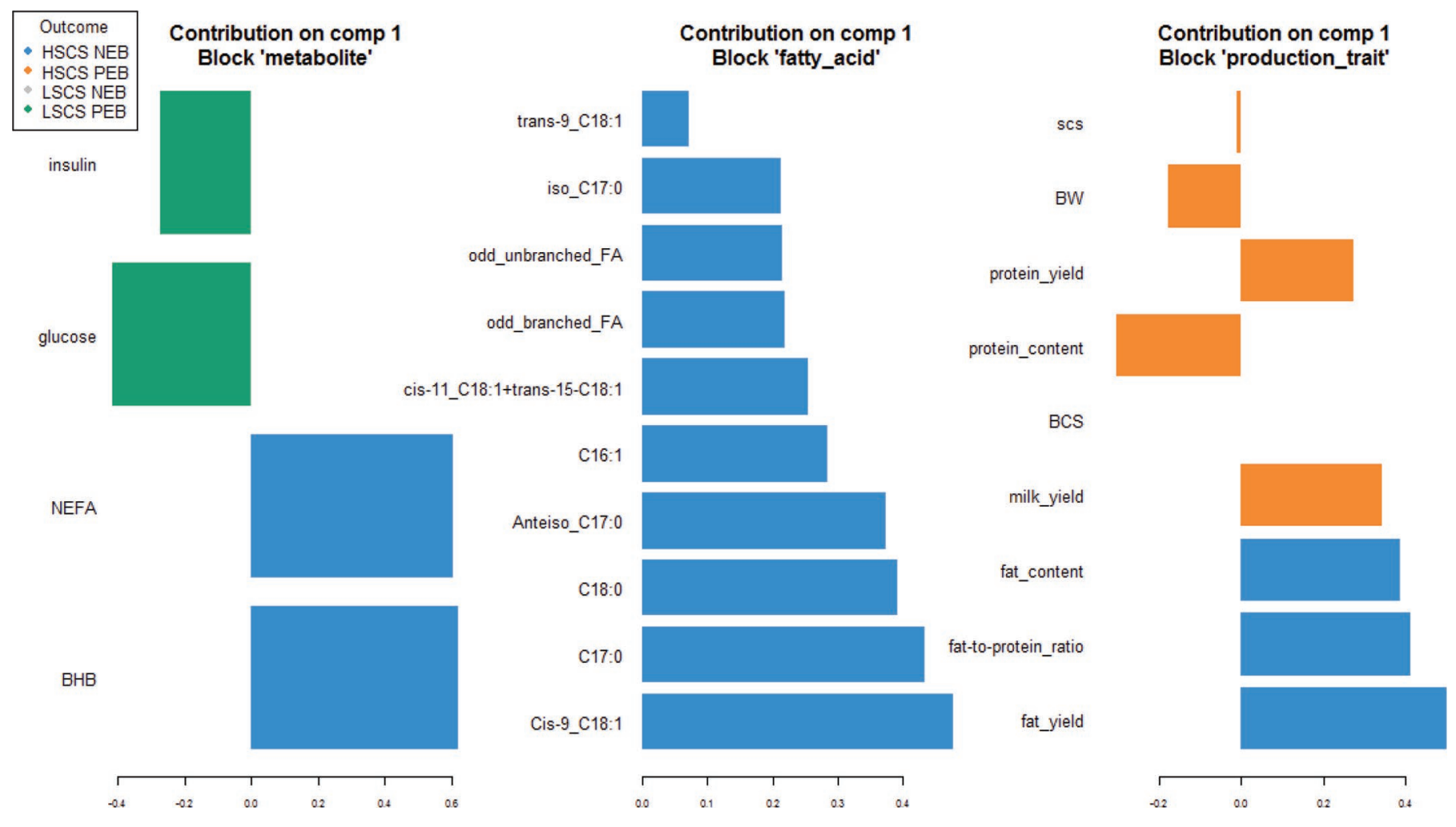

Figure 2. Visualization after a supervised classification by sparse partial least squares-discriminant analysis of the variables that best discriminate the 4 groups: high-SCS ewes in positive energy balance (HSCS PEB; $\mathrm{n}=12$, orange), low-SCS ewes in positive energy balance (LSCS PEB; $\mathrm{n}=12$, green), high-SCS ewes in negative energy balance (HSCS NEB; $\mathrm{n}=12$, blue), and low-SCS ewes in negative energy balance (LSCS NEB; $\mathrm{n}=12$, gray). The figure shows the variable weight (numerical scale) on the first principal component in 3 data set blocks: plasma metabolite concentrations, milk fatty acids (FA) yields, and production traits data set. Percentage of variance that explains the first principal component was 0.61 in the metabolite data set, 0.54 in the fatty acids data set, and 0.4 in the production traits data set, respectively. The analysis displayed was done for 48 ewes at 3 time points. NEFA = nonesterified fatty acids. 


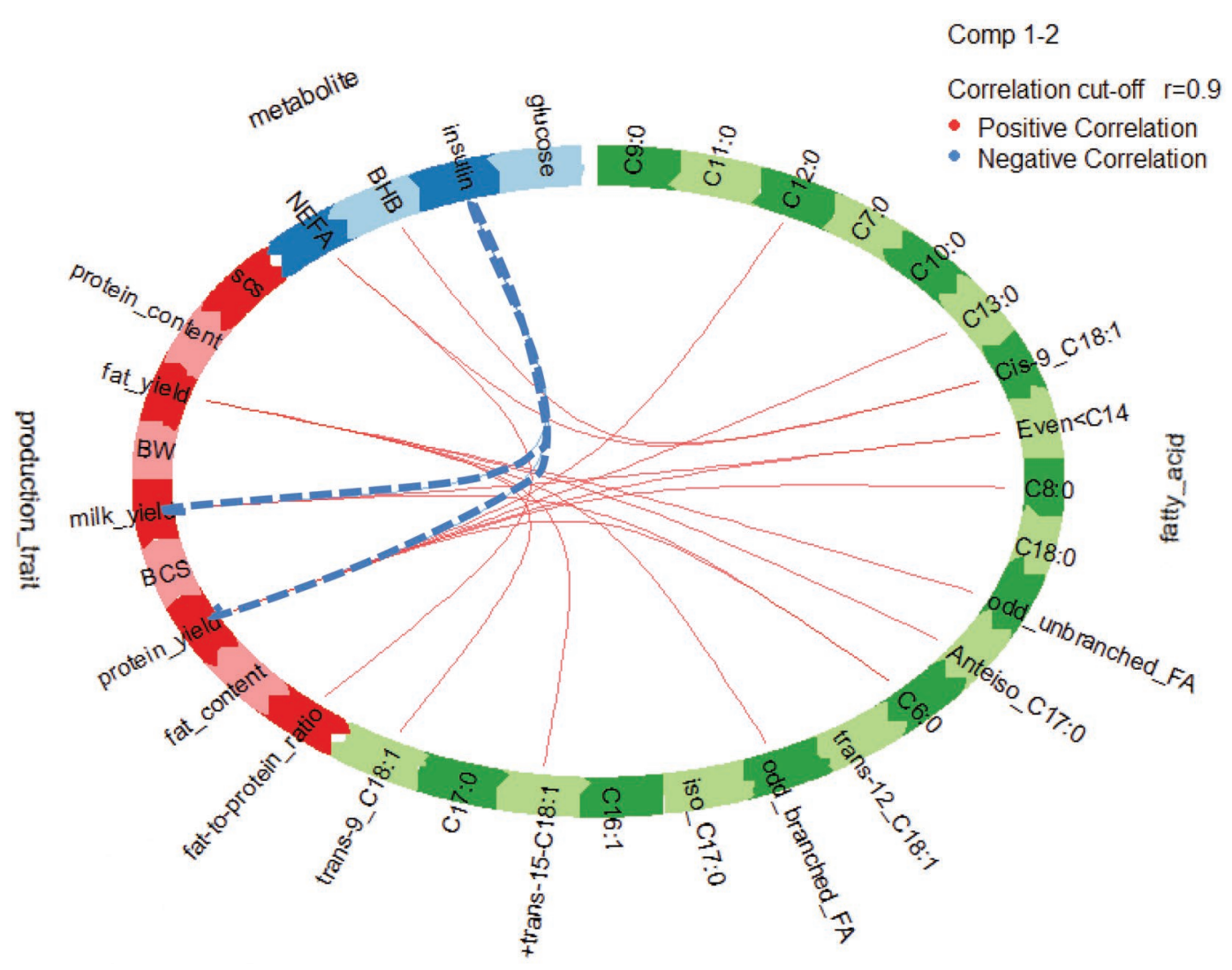

Figure 3. Correlation circle plot after a supervised classification by sparse partial least squares-discriminant analysis showing correlations between variables of 3 blocks of phenotypes (blood metabolite concentrations in blue, milk fatty acids (FA) yields in green, and production traits in red). The analysis was conducted using data from 48 ewes at 3 time points. Blue lines indicate negative correlations, and red lines indicate positive correlations. Intrablock correlations are not presented. Cutoff was fixed at 0.9. NEFA = nonesterified fatty acids. Color version available online.

(0.79 and 0.91, respectively), fat content (0.72 and 0.84, respectively), and milk long-chain FA yields (C16:1, C17:0, anteiso and iso C17:0, C18:0, cis-9 C18:1, cis-11 C18:1 + trans-15 C18:1, and trans-9 C18.1), with correlations ranging between 0.73 and 0.91 . In accordance, the fat yield and the fat-to-protein ratio were positively correlated with these long-chain FA yields, with correlations ranging from 0.61 to 0.93 . However, glucose concentration was negatively correlated with these long-chain FA yields, with correlation ranging between 0.7 and 0.8 . Insulin concentration was negatively correlated with milk short-chain FA yields (C6:0, C7:0, C8:0, C9:0, C10:0, C11:0, C12:0, and C13:0), with correlations ranging between 0.69 and -0.86 , whereas milk and protein yields were positively correlated with these milk FA yields, with correlations ranging between 0.71 and 0.92. Glucose and insulin concentrations were also negatively correlated with milk, fat, and protein yields, with correlations ranging between -0.69 and -0.91 .

The 10 milk FA yields highlighted during the first analysis (C16:1, C17.0, anteiso and iso C17:0, C18:0, cis-11 C18:1 + trans-15 C18:1, cis-9 C18:1, trans-9 C18:1, odd branched FA, and odd unbranched FA) were pulled with the production traits data set and the blood metabolite data set to create a new metaphenotype data set for the next step.

\section{Genes and Phenotypes Integration}

The second step was to identify those genes that best discriminated the 4 groups in relation to phenotypic data by performing a second sPLS-DA that included both meta-phenotype and gene count information. The RNA-seq data set included 20,017 normalized genes. The sPLS-DA was applied to integrate the 2 data sets on 24 ewes (6 from each of the 4 groups) using the 3 time points. Percentages of variance that explained the first and second PC were, respectively, 0.02 and 0.04 in the gene data set and 0.68 and 0.12 in the metaphenotype data set.

Figure 4 shows the phenotypes and the genes that best separated the 4 groups on PC1. The NEFA and 
BHB concentrations, fat-to-protein ratio, fat yield, fat content, cis- and trans-9 C18:1, C17:0, C18:0, anteiso C17:0, odd unbranched FA, C16:1, cis-11 C18:1 + trans-15 C18:1, odd branched FA, and iso C17.0 yields were the most discriminant variables in the phenotypes data set, whereas PDK4, FCGRT, CPT1A, KLF11, VSIG10L, SLC25A20, and KLF10 were the most discriminant genes. These were the main variables contributing to distinguish the high-SCS NEB ewes from the 3 other groups according to the sPLS-DA analysis (Figure 4).

The RV coefficient between the 2 transformed data sets was 0.77 , indicating a lower correlation than previously observed. Correlations higher than 0.9 between phenotypes and genes are shown in Figure 5. Expression of PDK4, FCGRT, KLF11, VSIG10L, KLF10, SLC25A20, and CPT1A was highly positively correlated with milk long-chain FA yields (C16:1, C17:0, anteiso and iso C17:0, C18:0, cis- and trans-9 C18:1, cis-11 C18:1 + trans-15 C18:1, odd unbranched FA, and odd branched FA) and fat yield, with correlations ranging between 0.71 and 0.96. Noteworthy, FCGRT, KLF11, and $C P T 1 A$ expressions were positively correlated with fat yield, fat-to-protein ratio, and BHB and NEFA concentrations, with the correlations ranging between 0.73 and 0.90 . The correlation table is displayed in Supplemental Table S3 (https://doi.org/10.3168/jds .2017-13479).

\section{$R T$-qPCR Validation of the Genes Identified by sPLS-DA Analysis}

Real-time qPCR was used to confirm the difference in expression of 7 genes (PDK4, FCGRT, CPT1A, KLF11, VSIG10L, SLC25A20, and KLF10) identified between the 4 groups during the sPLS-DA analysis. Gene expressions were tested on blood samples from the 24 ewes that had not been sequenced with the RNA-seq technique or used during the sPLS-DA analysis. The effect of group was significant or close to significant for PDK4, CPT1A, FCGRT, KLF10, and KLF11 expression (Table 1).

\section{Difference Between Genetic Lines for Fat-to-Protein Ratio}

Figure 6 shows fat-to-protein ratio (LSM $\pm \mathrm{SE})$ according to DIM and the genetic line measured in 1,025 ewes from 2005 to 2016. Results of the ANOVA are given in Supplemental Table S4 (https://doi.org/10 $.3168 /$ jds.2017-13479). The fat-to-protein ratio was significantly $(P \leq 0.05)$ higher in high-SCS ewes than in low-SCS ewes during early lactation (DIM <100). The difference between lines was largest in the earliest stage (average DIM $=6$ in primiparous ewes), but data were limited. Effects of DIM, year, milk production, and number of suckled lambs were also significant.
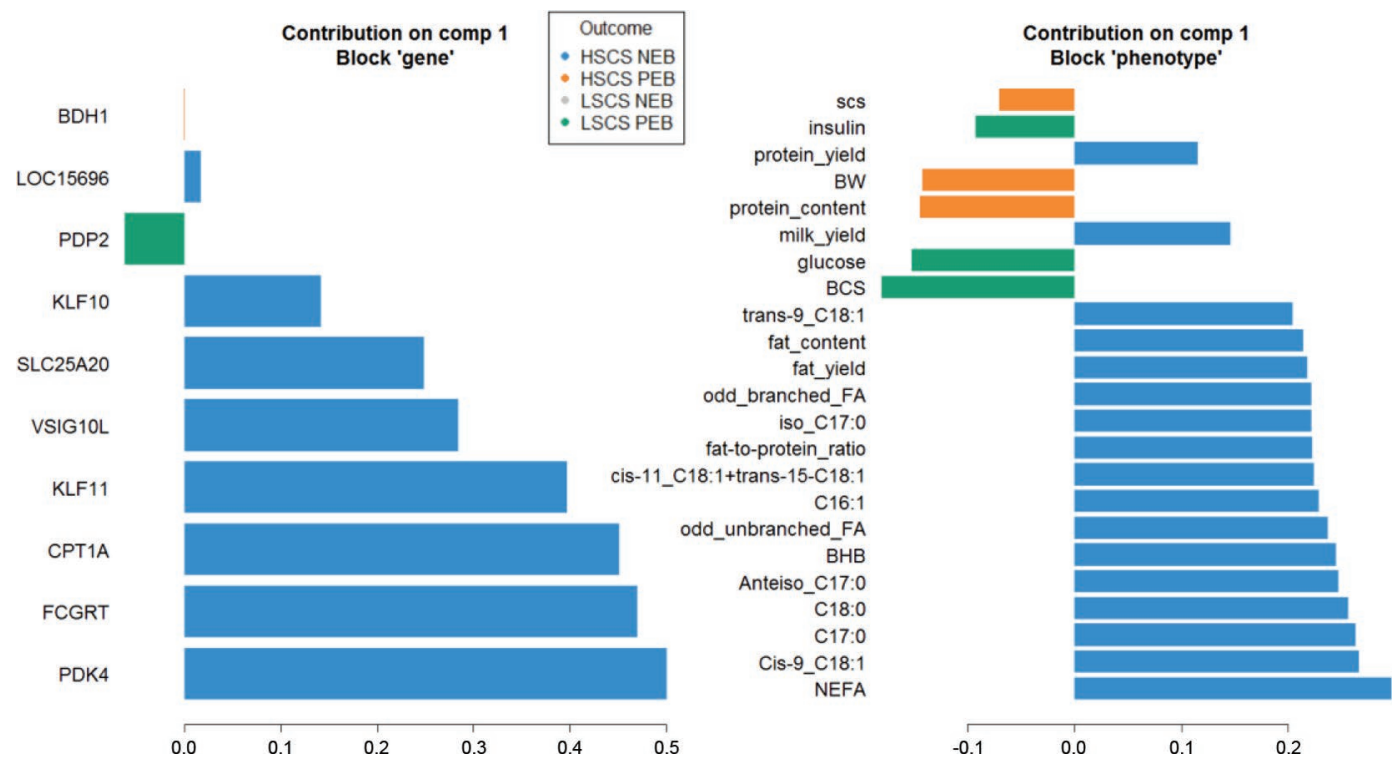

Figure 4. Visualization after a supervised classification by sparse partial least squares-discriminant analysis of the phenotypes and the genes that explained the largest part of variance between the 4 groups on the first principal component: high-SCS ewes in positive energy balance (HSCS PEB; $\mathrm{n}=6$, orange), low-SCS ewes in positive energy balance (LSCS PEB; $\mathrm{n}=6$, green), high-SCS ewes in negative energy balance (HSCS NEB; $n=6$, blue), and low-SCS ewes in negative energy balance (LSCS NEB; $n=6$, gray). The figure shows the variable weight (numerical scale) on the first principal component in 2 data set blocks: RNA-seq gene expression and a meta-phenotype data set. Percentage of variance that explains the first principal component was 0.68 in the meta-phenotype data set and 0.02 in the gene data set. The analysis was displayed with 3 time points in 24 ewes. $\mathrm{FA}=$ fatty acids; NEFA = nonesterified fatty acids. 
Table 1. Analysis of variance (linear mixed model) to test the group effect in high-SCS ewes in positive energy balance (PEB; $\mathrm{n}=6$ ), low-SCS ewes in PEB $(\mathrm{n}=6)$, high-SCS ewes in negative energy balance (NEB; $\mathrm{n}=6)$, and low-SCS ewes in NEB $(\mathrm{n}=12)$ on reverse-transcription quantitative PCR data ${ }^{1}$

\begin{tabular}{lcccccccc}
\hline Effect & CPT1A & SLC25A20 & VSIG10L & FCGRT & PDK4 & KLF10 & KLF11 & LRP12 \\
\hline Group & $4.4 \mathrm{E}-04$ & 0.12 & 0.88 & 0.07 & $2.011 \mathrm{E}-03$ & 0.10 & 0.02 \\
Time point & $6.2 \mathrm{E}-03$ & 0.09 & 0.22 & 0.18 & 0.13 & 0.06 & $1.1 \mathrm{E}-03$ & 0.18 \\
Milkref & $1.2 \mathrm{E}-08$ & $1.4 \mathrm{E}-06$ & 0.10 & $5.2 \mathrm{E}-07$ & $3.9 \mathrm{E}-05$ & $1.5 \mathrm{E}-05$ & $2.9 \mathrm{E}-09$ & $2.4 \mathrm{E}-03$ \\
\hline
\end{tabular}

${ }^{1}$ Model included time point and individual milk production reference (milkref).

\section{DISCUSSION}

\section{Mobilization of Body Reserves Highlighted Through Multiple Phenotypes and Gene Expressions}

Negative energy balance around parturition is known to lead to extensive mobilization of adipose triacylglycerols to meet energy requirements. These mobilized adipose tissue triacylglycerols result in high concentrations of plasma NEFA, which can be taken up by the liver and oxidized to produce ketone bodies (Dann et al., 2006; Goff, 2006). In the present study, NEFA and BHB were highly positively correlated with fat-toprotein ratio and fat content in accordance with Grieve et al. (1986). These authors demonstrated that the estimated energy balance in dairy cows was negatively correlated with milk fat percentage $(-0.07$ to -0.65$)$, positively correlated with milk protein percentage $(0.12$ to 0.47 ), and negatively correlated with the ratio of milk fat to protein $(-0.36$ to -0.74$)$ across data sets.

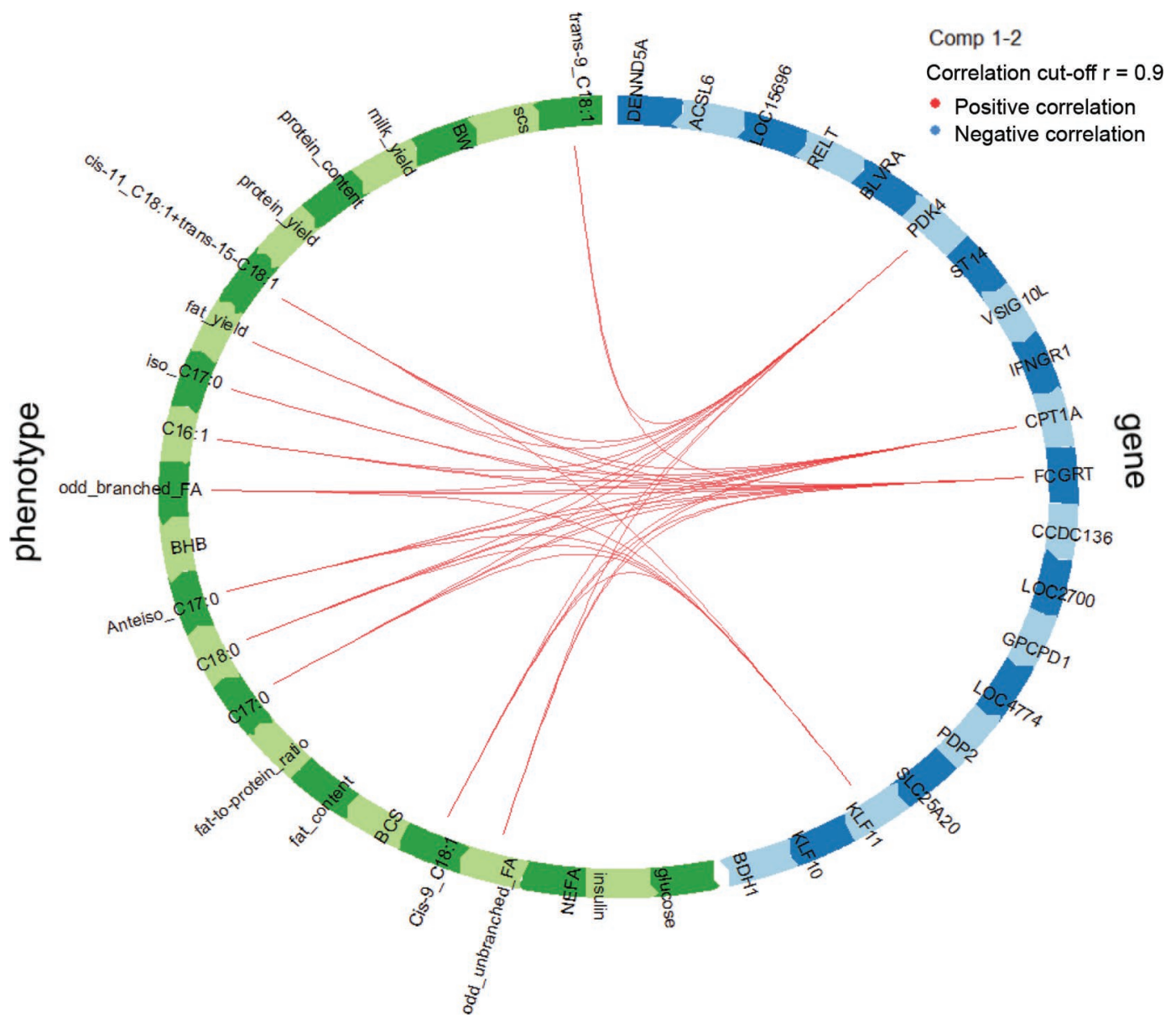

Figure 5. Correlation circle plot after a supervised classification by sparse partial least squares-discriminant analysis showing correlations between variables of 2 blocks (genes in blue; meta-block of phenotypes in green). The analysis was conducted using data from 24 ewes at 3 time points. Blue lines indicate negative correlations, and red lines indicate positive correlations. Intrablock correlations are not presented. Cutoff was fixed at $0.9 . \mathrm{FA}=$ fatty acids; NEFA = nonesterified fatty acids. Color version available online. 
For a fat-to-protein ratio greater than 1.5, the sensitivity and specificity to detect NEB were more than $40 \%$ and around $90 \%$, respectively (Heuer et al., 2000). According to their study and our results, the fat-toprotein ratio would therefore be a good predictor of energy status in dairy ewes and cows.

The NEFA and BHB concentrations were also highly positively correlated with milk long-chain FA yields (C16:1, C17:0, anteiso and iso $\mathrm{C} 17: 0, \mathrm{C} 18: 0$, cis and trans-9 C18:1, and cis-11 C18:1 + trans-15 C18:1). Individual FA in cow milk are derived from different sources (e.g., arterial uptake and de novo mammary gland synthesis). Even FA with chain lengths from C4 to $\mathrm{C} 16$ are produced de novo in the mammary gland from acetic and butyric acids originating from ruminal digestion of carbohydrates (Månsson, 2008). Odd- and branched-chain FA (C15:0, iso $\mathrm{C} 15: 0$, anteiso $\mathrm{C} 15: 0$, $\mathrm{C} 17: 0$, iso $\mathrm{C} 17: 0$, anteiso $\mathrm{C} 17: 0$, and $\mathrm{C} 17: 1$ ) are synthesized by ruminal bacteria and influenced indirectly by the diet (Vlaeminck et al., 2005), whereas long-chain FA (including C16:0) and PUFA are taken up by the mammary gland from the arterial blood and originate either from the digestive tract or from adipose tissue. As a result, the concentrations of individual FA in milk fat are dependent on the diet, which modulates both the FA profile of absorbed FA (Glasser et al., 2008) and adipose tissue mobilization (Gross et al., 2011).

In our study, the fat-to-protein ratio was positively correlated with some major milk long-chain FA yields (C16:1, C18:0, cis-9 C18:1), including intermediates from the ruminal biohydrogenation of dietary unsaturated FA (trans-9 C18:1 and cis-11 C18:1 + trans-15 C18:1) as reported by Stoop et al. (2009), who showed that a large deviation in the fat-to-protein ratio was associated with an increase in C16:0 and C18:0 milk concentration. Gross et al. (2011) studied the effect of a $49 \%$ energy restriction in 30 dairy cows at 100 DIM. In their study, oleic acid cis-9 C18:1 was significantly increased during the induced NEB, indicating that a considerable amount of adipose tissue had been mobilized. According to Van Haelst et al. (2008), an increased proportion of cis-9 18:1 in milk is of particular interest for the prediction of subclinical ketosis because the percentage of this FA in milk fat is high before the diagnosis of ketosis. Fat-to-protein ratio and NEFA and BHB concentrations were also positively correlated with odd- and branched-chain FA (C17:0, anteiso and iso C17:0). As each of these FA represents 0.4 to $0.8 \%$ of the adipose tissue FA in cattle (Gómez et al., 2015), an increased milk yield might be due to an increase in tissue fat mobilization. Moreover, iso and anteiso C17:0 are mainly synthesized in the rumen with branched AA as precursors (Keeney et al., 1962; Vlaeminck et al., 2005). In our experiment, because energy restriction was not accompanied by protein restriction, branchedchain AA were not limiting. Although branched C17:0 were not examined in previous investigations of the relationship between NEB and the milk FA profile (Van Haelst et al., 2008; Stoop et al., 2009; Gross et al., 2011), Gross et al. (2011) reported an increased proportion of cis-9 C17:1, derived from mammary desaturation of $\mathrm{C} 17: 0$, in the milk of cows subjected to a dietary restriction.

Thus, according to our results, the fat-to-protein ratio, NEFA and BHB concentrations, and long-chain
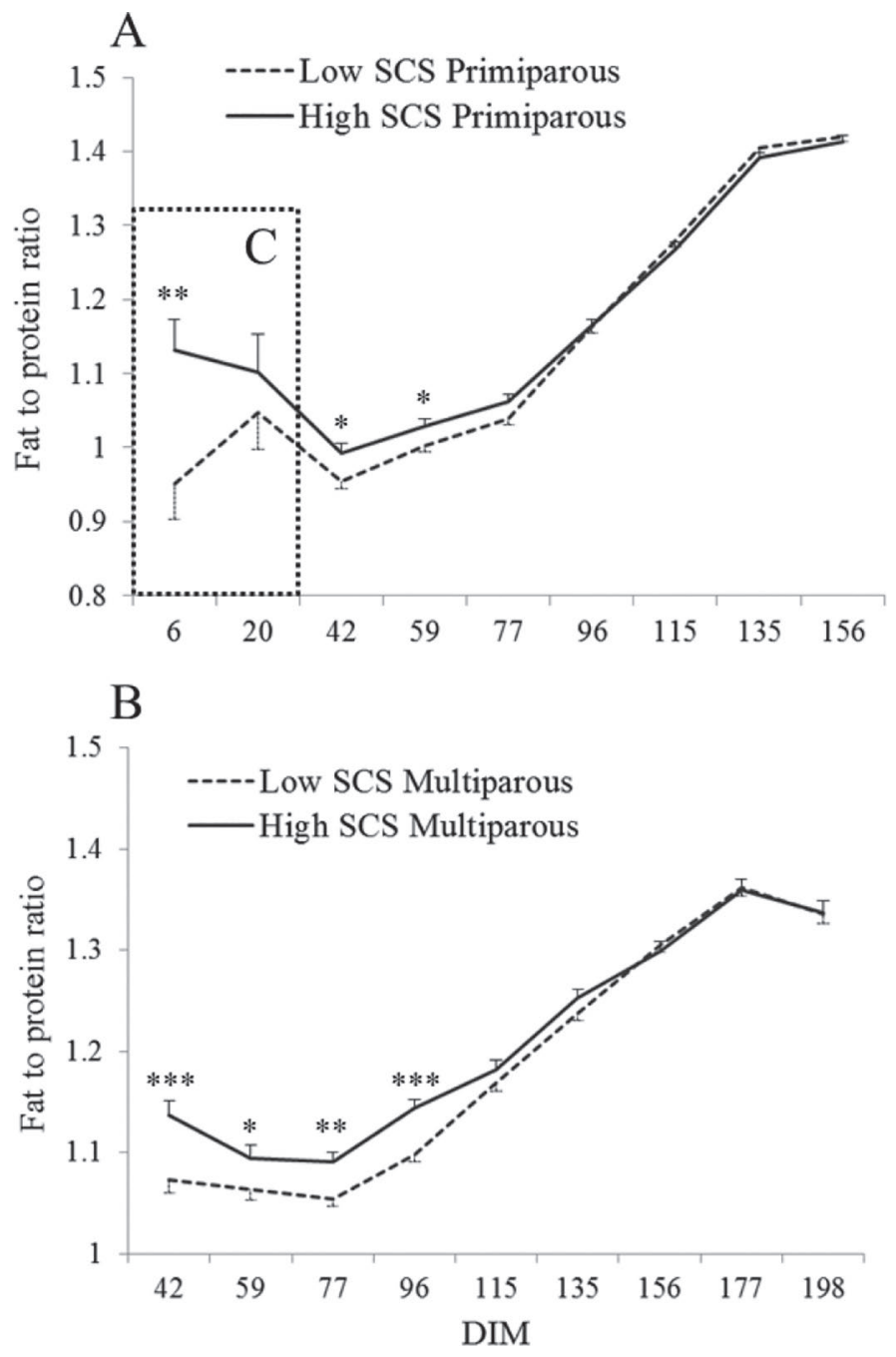

Figure 6. Fat-to-protein ratio (LSM $\pm \mathrm{SE}$ ) according to the DIM in low-SCS (dotted line) and high-SCS (solid line) ewes recorded in the field from 2005 to 2016. Mixed-model analyses were conducted separately on the morning test day of $(\mathrm{A})$ primiparous ewes $(\mathrm{n}=$ $1,025)$ and $(\mathrm{B})$ multiparous ewes $(\mathrm{n}=715)$ from 28 to 220 DIM. Two time points in early lactation at 6 and 20 DIM on average were also available for 70 primiparous ewes $(\mathrm{C})$. Significant effect of the genetic line within DIM is shown by asterisks. ${ }^{*} P<0.05$; ${ }^{* *} P<0.01$; ${ }^{* * *} P$ $<0.001$. 
FA constituted a robust set of phenotypes related to metabolic response. Our second analysis revealed that this set was positively correlated with $P D K 4, F C G R T$, KLF11, KLF10, SLC25A20, and CPT1A expressions. We had already shown the significant effects of energy restriction on CPT1A and PDK4 expression in blood cells in a previous study (Bouvier-Muller et al., 2017). CPT1A is indeed a key regulatory enzyme in FA oxidation as it catalyzes the formation of long-chain acyl-carnitine, which can then pass through the inner mitochondrial membrane and be used for $\beta$-oxidation in the mitochondria. SLC25A20 encodes for carnitineacylcarnitine translocase, which is responsible for transporting both carnitine-FA complexes and carnitine across the inner mitochondrial membrane. This gene, like CPT1A, seems to be essential to the FA oxidation pathway and utilization of FA as fuel sources. Moreover, PDK4 expression was highly positively correlated with our phenotypes of interest. PDK4 inactivates pyruvate dehydrogenase, inhibiting the utilization of pyruvate for acetyl-CoA synthesis and hence blocking glucose oxidation and favoring FA oxidation for energy production (Harris et al., 2002).

Similarly to PDK4 and CPT1A, KLF10 and KLF11 are under the control of transcription factor PPAR $\alpha$ (Rakhshandehroo et al., 2009; Song et al., 2010), which belongs to the nuclear hormone receptor superfamily and has been identified as a master regulator of lipid metabolism in liver (Kersten et al., 2000; Mandard et al., 2004). KLF proteins bind to the GC box or CACCC boxes of genes involved in key biological cellular functions, including cell proliferation, differentiation, and apoptosis. However, KLF10 and KLF11 have also been established as transcriptional regulators of hepatic lipid homeostasis (Guillaumond et al., 2010; Zhang et al., 2013). In particular, KLF11 might have stimulatory effects on the expression of genes involved in FA oxidation (Zhang et al., 2013), which is consistent with our results.

Expression of FCGRT was also highly positively correlated with our phenotypes of interest. This gene encodes the receptor FcRn that binds the Fc region of monomeric IgG. This protein is involved in transporting maternal immunity within the mammary lumen for colostrum synthesis (Story et al., 1994) and protects IgG from fast degradation throughout life (Chaudhury et al., 2003). FcRn therefore plays a crucial role in the metabolism of IgG in cattle, as reported by Cervenak and Kacskovics (2009). However, to our knowledge, there is no explanation in the literature of the link between FCGRT expression and lipid metabolism. Further studies are needed to understand this possible relationship.

\section{Enhanced Sensitivity to Energy Restriction of High-SCS Ewes Revealed Through a Data Integration Approach}

Altogether, the integration of phenotypic and transcriptomic data provided firm and consistent results on the relationship between metabolic parameters. All the described variables in this robust set of metabolic parameters contributed to distinguishing the highSCS energy-restricted ewes from the other groups, in accordance with our previous study, which evidenced an interaction between genetic background and energy balance based solely on weight, BHB, and NEFA (Bouvier-Muller et al., 2016). Indeed, high-SCS ewes showed a greater decrease in BW and higher NEFA and BHB concentrations than low-SCS ewes when subjected to energy restriction. The present study confirmed that greater mobilization of adipose tissue occurred in high-SCS ewes than in low-SCS ewes, as reflected by the high value of the milk long-chain FA used to discriminate energy-restricted high-SCS ewes. These results strongly suggest that long-chain FA were exported from adipose tissue to the blood and accumulated in the mammary gland, leading, in particular, to an increase in the fat yield and fat-to-protein ratio of the milk. The considerable increase in blood NEFA concentration also led to enhanced FA oxidation in the blood cells, as reflected by the importance of $P D K 4$, CPT1A, SLC25A20, KLF10, and KLF11 expression in discriminating energy-restricted high-SCS ewes from the other 3 groups.

Fat-to-protein ratio was highly positively correlated with metabolic parameters related to energy balance in early lactation and seemed to provide an inexpensive and easy tool for characterizing a negative energy balance during this period. The expanded data set showed that fat-to-protein ratio was also significantly higher in high-SCS ewes than in low-SCS ewes during the first 2 mo of lactation. As the model also included the effect of milk production, this difference was not due to a difference in milk production. In addition, the rams used to create the divergent low-SCS and high-SCS lines were chosen for their similar and favorable EBV for milk production to avoid confounding effects due to an indirect response to selection for production traits. Altogether, these results confirmed our assumption that high-SCS ewes are more sensitive to energy restriction than lowSCS ewes in early lactation irrespective of their milk production level. In accordance, Koeck et al. (2014) determined the genetic parameters for milk BHB of Canadian Holstein cows in early first lactation and examined their genetic association with SCS. The authors showed a moderate positive genetic correlation between 
milk BHB on the first test day and the SCS in early lactation (0.19 for 5-20 DIM and 0.11 for 21-40 DIM). Similarly, Zwald et al. (2004) calculated the genetic correlations between health traits from 161,622 cows in 646 herds and reported a modest but significant correlation (0.17) between mastitis and ketosis, suggesting a partially shared genetic predisposition for these diseases. Altogether, these results confirmed that selection for low SCS involves having animals more robust, with potentially fewer metabolic disorders such as ketosis, and a better response to NEB in early lactation.

\section{CONCLUSIONS}

Integration of transcriptomic and phenotypic data revealed high correlations between the fat-to-protein ratio, BHB and NEFA concentrations, milk long-chain FA yields, and the expression of genes involved in FA oxidation and its regulation. Although these correlations were already well known in dairy cattle, this is the first report to describe a phenotypic and transcriptomic integrative characterization of energy restriction in dairy ewes. These metabolic parameters and genes contributed to distinguishing the response to energy restriction of ewes selected for high or low SCS, suggesting that ewes genetically susceptible to mastitis were more sensitive to energy restriction than genetically resistant ewes. The results confirmed the hypothesis of a favorable genetic association between resistance to mastitis and metabolic adaptation to energy shortage and suggested new ways for genetic improvement in dairy ruminants. In particular, this study suggests that the fat-to-protein ratio could be used as a low-cost monitoring tool of poor health during the most critical phases of lactation and as an important indicator trait to improve robustness in dairy ruminants through selection.

\section{ACKNOWLEDGMENTS}

This work was supported by grants from the RUMINFLAME project as part of the INRA MetaProgramme Gestion Intégrée de la Santé Animale (GISA). Gratitude is extended to the technical staff of La Fage (Roquefort, France) experimental farm for assisting with technical support, animal care, and data collection.

\section{REFERENCES}

Barkema, H. W., M. J. Green, A. J. Bradley, and R. N. Zadoks. 2009. Invited review: The role of contagious disease in udder health. J. Dairy Sci. 92:4717-4729. https://doi.org/10.3168/jds.2009-2347.

Bergonier, D., and X. Berthelot. 2003. New advances in epizootiology and control of ewe mastitis. Livest. Prod. Sci. 79:1-16. https://doi .org/10.1016/S0301-6226(02)00145-8.
Bergonier, D., R. de Crémoux, R. Rupp, G. Lagriffoul, and X. Berthelot. 2003. Mastitis of dairy small ruminants. Vet. Res. 34:689-716. https://doi.org/10.1051/vetres:2003030.

Bonnefont, C. M., M. Toufeer, C. Caubet, E. Foulon, C. Tasca, M.-R. Aurel, D. Bergonier, S. Boullier, C. Robert-Granié, G. Foucras, and R. Rupp. 2011. Transcriptomic analysis of milk somatic cells in mastitis resistant and susceptible sheep upon challenge with Staphylococcus epidermidis and Staphylococcus aureus. BMC Genomics 12:208. https://doi.org/10.1186/1471-2164-12-208.

Bouvier-Muller, J., C. Allain, F. Enjalbert, G. Tabouret, D. Portes, C. Caubet, C. Tasca, G. Foucras, and R. Rupp. 2016. Response to dietary-induced energy restriction in dairy sheep divergently selected for resistance or susceptibility to mastitis. J. Dairy Sci. 99:480-492. https://doi.org/10.3168/jds.2015-9785.

Bouvier-Muller, J., C. Allain, G. Tabouret, F. Enjalbert, D. Portes, C. Noirot, R. Rupp, and G. Foucras. 2017. Whole blood transcriptome analysis reveals potential competition in metabolic pathways between negative energy balance and response to inflammatory challenge. Sci. Rep. 7:2379. https://doi.org/10.1038/s41598-017 $-02391-y$.

Cervenak, J., and I. Kacskovics. 2009. The neonatal Fc receptor plays a crucial role in the metabolism of IgG in livestock animals. Vet. Immunol. Immunopathol. 128:171-177. https://doi.org/10.1016/j vetimm.2008.10.300.

Chaudhury, C., S. Mehnaz, J. M. Robinson, W. L. Hayton, D. K. Pearl, D. C. Roopenian, and C. L. Anderson. 2003. The major histocompatibility complex-related Fc receptor for IgG (FcRn) binds albumin and prolongs its lifespan. J. Exp. Med. 197:315-322. https://doi.org/10.1084/jem.20021829.

Dann, H. M., N. B. Litherland, J. P. Underwood, M. Bionaz, A. D'Angelo, J. W. McFadden, and J. K. Drackley. 2006. Diets during far-off and close-up dry periods affect periparturient metabolism and lactation in multiparous cows. J. Dairy Sci. 89:3563-3577. https://doi.org/10.3168/jds.S0022-0302(06)72396-7.

Drackley, J. K. 1999. Biology of dairy cows during the transition period: The final frontier? J. Dairy Sci. 82:2259-2273. https://doi .org/10.3168/jds.S0022-0302(99)75474-3.

Glasser, F., M. Doreau, A. Ferlay, and Y. Chilliard. 2007. Technical note: Estimation of milk fatty acid yield from milk fat data. J. Dairy Sci. 90:2302-2304. https://doi.org/10.3168/jds.2006-870.

Glasser, F., P. Schmidely, D. Sauvant, and D. Doreau. 2008. Digestion of fatty acids in ruminants: A meta-analysis of flows and variation factors: 2. C18 fatty acids. Animal 2:691-704. https://doi.org/10 $.1017 /$ S1751731108002036.

Goff, J. P. 2006. Major advances in our understanding of nutritional influences on bovine health. J. Dairy Sci. 89:1292-1301. https:// doi.org/10.3168/jds.S0022-0302(06)72197-X.

Gómez, I., J. A. Mendizabal, M. V. Sarriés, K. Insausti, P. Albertí, C. Realini, M. Pérez-Juan, M. A. Oliver, A. Purroy, and M. J. Beriain. 2015. Fatty acid composition of young Holstein bulls fed whole linseed and rumen-protected conjugated linoleic acid enriched diets. Livest. Sci. 180:106-112. https://doi.org/10.1016/j .livsci.2015.07.023.

Grieve, D. G., S. Korver, Y. S. Rijpkema, and G. Hof. 1986. Relationship between milk composition and some nutritional parameters in early lactation. Livest. Prod. Sci. 14:239-254. https://doi.org/10 .1016/0301-6226(86)90083-7.

Gross, J., H. A. van Dorland, R. M. Bruckmaier, and F. J. Schwarz. 2011. Milk fatty acid profile related to energy balance in dairy cows. J. Dairy Res. 78:479-488. https://doi.org/10.1017/ S0022029911000550.

Guillaumond, F., A. Gréchez-Cassiau, M. Subramaniam, S. Brangolo, B. Peteri-Brünback, B. Staels, C. Fiévet, T. C. Spelsberg, F. Delaunay, and M. Teboul. 2010. Krüppel-like factor KLF10 is a link between the circadian clock and metabolism in liver. Mol. Cell. Biol. 30:3059-3070. https://doi.org/10.1128/MCB.01141-09.

Harris, R. A., M. M. Bowker-Kinley, B. Huang, and P. Wu. 2002 Regulation of the activity of the pyruvate dehydrogenase complex. Adv. Enzyme Regul. 42:249-259. https://doi.org/10.1016/S0065 $-2571(01) 00061-9$. 
Heringstad, B., G. Klemetsdal, and J. Ruane. 2000. Selection for mastitis resistance in dairy cattle: A review with focus on the situation in the Nordic countries. Livest. Prod. Sci. 64:95-106. https://doi .org/10.1016/S0301-6226(99)00128-1.

Heuer, C., W. M. Van Straalen, Y. H. Schukken, A. Dirkzwager, and J. P. T. M. Noordhuizen. 2000. Prediction of energy balance in a high yielding dairy herd in early lactation: Model development and precision. Livest. Prod. Sci. 65:91-105. https://doi.org/10.1016/ S0301-6226(99)00177-3.

Jánosi, S., M. Kulcsár, P. Kóródi, L. Kátai, J. Reiczigel, S. J. Dieleman, J. A. Nikolic, G. Sályi, P. Ribiczey-Szabó, and G. Huszenicza. 2003. Energy imbalance related predisposition to mastitis in group-fed high-producing postpartum dairy cows. Acta Vet. Hung. 51:409-424. https://doi.org/10.1556/AVet.51.2003.3.14.

Jenkins, T. C. 2010. Technical note: Common analytical errors yielding inaccurate results during analysis of fatty acids in feed and digesta samples. J. Dairy Sci. 93:1170-1174. https://doi.org/10 $.3168 /$ jds.2009-2509.

Keeney, M., I. Katz, and M. J. Allison. 1962. On the probable origin of some milk fat acids in rumen microbial lipids. J. Am. Oil Chem. Soc. 39:198-201. https://doi.org/10.1007/BF02635818.

Kehrli, M. E., and D. E. Shuster. 1994. Factors affecting milk somatic cells and their role in health of the bovine mammary gland. J. Dairy Sci. 77:619-627. https://doi.org/10.3168/jds.S0022 -0302(94)76992-7.

Kersten, S., B. Desvergne, and W. Wahli. 2000. Roles of PPARs in health and disease. Nature 405:421-424. https://doi.org/10.1038/ 35013000 .

Koeck, A., J. Jamrozik, F. S. Schenkel, R. K. Moore, D. M. Lefebvre, D. F. Kelton, and F. Miglior. 2014. Genetic analysis of milk $\beta$-hydroxybutyrate and its association with fat-to-protein ratio, body condition score, clinical ketosis, and displaced abomasum in early first lactation of Canadian Holsteins. J. Dairy Sci. 97:72867292. https://doi.org/10.3168/jds.2014-8405.

Lê Cao, K.-A., S. Boitard, and P. Besse. 2011. Sparse PLS discriminant analysis: Biologically relevant feature selection and graphical displays for multiclass problems. BMC Bioinformatics 12:253. https://doi.org/10.1186/1471-2105-12-253.

Lê Cao, K.-A., I. González, and S. Déjean. 2009. integrOmics: An $\mathrm{R}$ package to unravel relationships between two omics datasets. Bioinformatics 25:2855-2856. https://doi.org/10.1093/ bioinformatics/btp515.

Mandard, S., M. Müller, and S. Kersten. 2004. Peroxisome proliferator-activated receptor $\alpha$ target genes. Cell. Mol. Life Sci. 61:393416. https://doi.org/10.1007/s00018-003-3216-3.

Månsson, H. L. 2008. Fatty acids in bovine milk fat. Food Nutr. Res. 52:1821. https://doi.org/10.3402/fnr.v52i0.1821.

Mrode, R. A., and G. J. T. Swanson. 1996. Genetic and statistical properties of somatic cell count and its suitability as an indirect means of reducing the incidence of mastitis in dairy cattle. Anim. Breed. Abstr. 64:847-857.

Nyman, A. K., U. Emanuelson, K. Holtenius, K. L. Ingvartsen, T. Larsen, and K. P. Waller. 2008. Metabolites and immune variables associated with somatic cell counts of primiparous dairy cows. J. Dairy Sci. 91:2996-3009. https://doi.org/10.3168/jds.2007-0969.

Paape, M., J. Mehrzad, X. Zhao, J. Detilleux, and C. Burvenich. 2002. Defense of the bovine mammary gland by polymorphonuclear neutrophil leukocytes. J. Mammary Gland Biol. Neoplasia 7:109-121.

Rakhshandehroo, M., G. Hooiveld, M. Müller, and S. Kersten. 2009 Comparative analysis of gene regulation by the transcription factor PPAR $\alpha$ between mouse and human. PLoS One 4:e6796. https:// doi.org/10.1371/journal.pone.0006796.

Robert, P., and Y. Escoufier. 1976. A unifying tool for linear multivariate statistical methods: The RV- coefficient. J. R. Stat. Soc. Ser. C Appl. Stat. 25:257-265. https://doi.org/10.2307/2347233.
Rupp, R., D. Bergonier, S. Dion, M. C. Hygonenq, M. R. Aurel, C. Robert-Granié, and G. Foucras. 2009. Response to somatic cell count-based selection for mastitis resistance in a divergent selection experiment in sheep. J. Dairy Sci. 92:1203-1219. https://doi .org/10.3168/jds.2008-1435.

Rupp, R., and D. Boichard. 2003. Genetics of resistance to mastitis in dairy cattle. Vet. Res. 34:671-688. https://doi.org/10.1051/vetres: 2003020.

Rupp, R., and G. Foucras. 2010. Genetics of Mastitis in Dairy Ruminants. 3rd ed. S. C. Bishop, R. F. E. Axford, F. W. Nicholas, and J. B. Owen, ed. CABI, Wallingford, UK.

Russel, A. J. F., J. M. Doney, and R. G. Gunn. 1969. Subjective assessment of body fat in live sheep. J. Agric. Sci. 72:451-454. https://doi.org/10.1017/S0021859600024874.

Song, S., R. R. Attia, S. Connaughton, M. I. Niesen, G. C. Ness, M. B. Elam, R. T. Hori, G. A. Cook, and E. A. Park. 2010. Peroxisome proliferator activated receptor alpha (PPARalpha) and PPAR gamma coactivator (PGC-1alpha) induce carnitine palmitoyltransferase IA (CPT-1A) via independent gene elements. Mol. Cell. Endocrinol. 325:54-63. https://doi.org/10.1016/j.mce.2010 .05.019.

Sordillo, L. M. 2005. Factors affecting mammary gland immunity and mastitis susceptibility. Livest. Prod. Sci. 98:89-99. https://doi .org/10.1016/j.livprodsci.2005.10.017.

Stoop, W. M., H. Bovenhuis, J. M. L. Heck, and J. M. van Arendonk. 2009. Effect of lactation stage and energy status on milk fat composition of Holstein-Friesian cows. J. Dairy Sci. 92:1469-1478. https://doi.org/10.3168/jds.2008-1468.

Story, C. M., J. E. Mikulska, and N. E. Simister. 1994. A major histocompatibility complex class I-like Fc receptor cloned from human placenta: Possible role in transfer of immunoglobulin G from mother to fetus. J. Exp. Med. 180:2377-2381.

Suriyasathaporn, W., C. Heuer, E. N. Noordhuizen-Stassen, and Y. H. Schukken. 2000. Hyperketonemia and the impairment of udder defense: A review. Vet. Res. 31:397-412. https://doi.org/10.1051/ vetres:2000128.

Troegeler-Meynadier, A., S. Puaut, Y. Farizon, and F. Enjalbert. 2014. Effects of the heating process of soybean oil and seeds on fatty acid biohydrogenation in vitro. J. Dairy Sci. 97:5657-5667. https://doi.org/10.3168/jds.2013-7783.

Van Haelst, Y. N. T., A. Beeckman, A. T. M. Van Knegsel, and V. Fievez. 2008. Short communication: Elevated concentrations of oleic acid and long-chain fatty acids in milk fat of multiparous subclinical ketotic cows. J. Dairy Sci. 91:4683-4686. https://doi .org $/ 10.3168 / j d s .2008-1375$.

Vlaeminck, B., C. Dufour, A. M. van Vuuren, A. R. J. Cabrita, R. J. Dewhurst, D. Demeyer, and V. Fievez. 2005. Use of odd and branched-chain fatty acids in rumen contents and milk as a potential microbial marker. J. Dairy Sci. 88:1031-1042. https://doi.org/ 10.3168/jds.S0022-0302(05)72771-5.

Wellnitz, O., and R. M. Bruckmaier. 2012. The innate immune response of the bovine mammary gland to bacterial infection. Vet. J. 192:148-152. https://doi.org/10.1016/j.tvjl.2011.09.013.

Wells, S. J., S. L. Ott, and A. H. Seitzinger. 1998. Key health issues for dairy cattle - New and old. J. Dairy Sci. 81:3029-3035.

Zhang, H., Q. Chen, M. Yang, B. Zhu, Y. Cui, Y. Xue, N. Gong, A. Cui, M. Wang, L. Shen, S. Zhang, F. Fang, and Y. Chang. 2013. Mouse KLF11 regulates hepatic lipid metabolism. J. Hepatol. 58:763-770. https://doi.org/10.1016/j.jhep.2012.11.024.

Zwald, N. R., K. A. Weigel, Y. M. Chang, R. D. Welper, and J. S. Clay. 2004. Genetic selection for health traits using producer-recorded data. II. Genetic correlations, disease probabilities, and relationships with existing traits. J. Dairy Sci. 87:4295-4302. https://doi .org/10.3168/jds.S0022-0302(04)73574-2. 